\title{
Efficacy of pEgr-1-endostatin combined with ionizing radiation on hypoxic conditions in nude mice bearing SKOV3 ovarian carcinoma
}

\author{
YONG-CHUN ZHANG ${ }^{1 *}, \mathrm{XIU}_{\text {MEI LI }}{ }^{2 *}, \mathrm{ZHUANG} \mathrm{YU}^{1}, \mathrm{XIAO-LI} \mathrm{SHI}{ }^{1}, \mathrm{YONG} \mathrm{LI}^{3}$ and WAN-LIN WANG ${ }^{1}$ \\ Departments of ${ }^{1}$ Oncology, ${ }^{2}$ Ultrasound and ${ }^{3}$ Gynecology, The Affiliated Hospital of Qingdao University, \\ Qingdao, Shandong 266003, P.R. China
}

Received June 26, 2015; Accepted September 6, 2016

DOI: $10.3892 / 01.2017 .5559$

\begin{abstract}
Hypoxia occurs in a wide range of solid tumors, and is strongly associated with radio-resistance of malignant tumors. The aim of the present study was to investigate the effect of endostatin combined with ionizing radiation (IR) on hypoxic conditions. A total of 24 mice bearing SKOV3 ovarian carcinoma were divided into three groups. Following injection with pEgr-1-endostatin plasmid for $12 \mathrm{~h}$, the mice in the endostatin-IR-treated group were exposed to $300 \mathrm{cGy} / \mathrm{min}$ $\mathrm{X}$-ray for $48 \mathrm{~h}$, and the IR-treated group was exposed to the same condition. Then, the expression of endostatin, hypoxia-inducible factor (HIF)-1 $\alpha$ and vascular endothelial growth factor (VEGF) was detected by reverse transcription-polymerase chain reaction, ELISA, immunohistochemistry and western blotting. In addition, the tumor microvessel density (MVD) was examined by immunohistochemistry analysis of cluster of differentiation 31-positive cells. The results revealed that pEgr-1-endostatin was successfully induced by IR. The level of endostatin messenger RNA in the endostatin-IR-treated group was significantly higher than that in the control and IR-treated groups $(\mathrm{F}=380.078, \mathrm{P}<0.001)$. Statistical differences were also examined at the protein level by western blotting and ELISA. An obvious increase in MVD was observed in the IR-treated group compared with that in the control group $(t=7.040, \mathrm{P}<0.001)$, and a significant decrease in MVD was observed in the endostatin-IR-treated group compared with that in the control group $(t=18.153, \mathrm{P}<0.001)$. By comparing the morphology of the tumor vasculature in the three groups, it was noticed that the microvessels in the endostatin-IR-treated
\end{abstract}

Correspondence to: Dr Yong-Chun Zhang, Department of Oncology, The Affiliated Hospital of Qingdao University, 16 Jiangsu Road, Qingdao, Shandong 266003, P.R. China

E-mail: summermed@126.com

*Contributed equally

Key words: endostatin, ionizing radiation, hypoxia, SKOV3, nude mice, angiogenesis group were more regularly distributed and had fewer giant branches than those in the IR-treated group. Further investigation revealed that the expression levels of HIF-1 $\alpha$ and VEGF in the endostatin-IR-treated group were lower compared with those in the control $(t=5.339, \mathrm{P}=0.001$; and $t=13.880, \mathrm{P}<0.001$, respectively) and the IR-treated groups $(t=12.930, \mathrm{P}<0.001$; and $t=14.050, \mathrm{P}<0.001$, respectively). Our findings suggested that endostatin decreased the number of microvessels via the HIF-1/VEGF signaling pathway, and that pEgr-1-endostatin combined with IR may improve hypoxic conditions and may be a novel approach for treating solid tumors.

\section{Introduction}

Radiotherapy is one of the most important treatments for solid tumors; however, hypoxia occurs in a wide range of solid tumors, and is strongly associated with radio-resistance of malignant tumors $(1,2)$. Hypoxia can trigger the angiogenic switch by activating the transcription of hypoxia-inducible factor (HIF)-1 $\alpha(3,4)$. Aberrant microvessels, which exhibit severe structural alterations (often a dilated, tortuous, elongated and even saccular morphology) and dysfunction serve critical roles in the development of hypoxia $(5,6)$.

HIF-1, as the crucial mediator of the adaptive response of cells to hypoxia, is a HIF-1 $\alpha / \mathrm{HIF}-1 \beta$ heterodimer (7). The expression of HIF- $1 \alpha$ increases under hypoxic conditions, since HIF- $1 \alpha$ can protect proteins from ubiquitination and proteasomal degradation (8). HIF-1 can induce the expression of $>200$ functional genes that participate in cell survival by binding to the hypoxia response element in the target promoters (9). HIF-1 $\alpha$, the oxygen sensitive subunit of HIF-1, is stabilized and forms a dimer with HIF-1 $\beta$ in the nucleus during hypoxia, which can release angiogenesis promoters such as vascular endothelial growth factor (VEGF) $(10,11)$. This process involves a series of genes associated with tumor progression, angiogenesis, glycolysis, cellular growth, invasion and apoptosis $(11,12)$.

VEGF, a downstream target of HIF-1 $\alpha$, regulates the cell response to hypoxia, and serves a significant role in tumor angiogenesis $(13,14)$. As the key angiogenic promoter, the majority of anti-angiogenic strategies that can selectively inhibit the abnormal vasculature commonly present in solid tumors have been developed to block the VEGF signaling 
Table I. Primers for polymerase chain reaction amplification.

\begin{tabular}{llc}
\hline Gene & \multicolumn{1}{c}{ Primer sequence } & Amplicon (bp) \\
\hline HIF-1 $\alpha$ & Forward: 5'-CTT CTG GAT GCT GGT GAT TTG-3' & 245 \\
VEGF & Reverse: 5'-TAT ACG TGA ATG TGG CCT GTG-3' & 418 \\
& Forward: 5'-AGG AGG GCA GAA TCA TCA CG-3' & \\
Endostatin & Reverse: 5'-TAT GTG CTG GCC TTG GTG AG-3' & 422 \\
& Forward: 5'-GGA ATT CAT GCA CAG CCA CCG CGA CTT C-3' \\
GAPDH & Reverse: 5'-CGG GAT CCT ACT TGG AGG CAG TCA TG-3' & 450 \\
& Forward: 5'-TGA AGG TCG GTG TGA ACG GAT TTG GC-3' \\
\hline
\end{tabular}

HIF, hypoxia-inducible factor; VEGF, vascular endothelial growth factor.

pathway $(6,15)$. Preclinical data have demonstrated that recombinant human endostatin can improve radio-sensitivity in a nude mouse model bearing nasopharyngeal carcinomas by reducing the expression of VEGF (16).

Endostatin is an endogenous $20-\mathrm{kDa} \mathrm{COOH}$-terminal fragment of collagen XVIII, and is activated by proteolytic processing $(17,18)$. It was first identified in murine hemangioendothelioma cells, and was subsequently demonstrated to be a potent angiogenesis inhibitor (19). However, there are limited reports on the improvement of radio-resistance by endostatin. Genetic radiotherapy, a new paradigm for cancer treatment, is a combination of gene therapy and radiotherapy (20), and may facilitate the use of endostatin in cancer treatment. Our previous study successfully combined gene therapy with irradiation mediated by the pEgr-1 promoter (21). Further studies to investigate the effect of pEgr-1-endostatin in combination with ionizing radiation (IR) on improving radio-resistance in hypoxic conditions should be performed.

In the present study, a nude mouse xenograft model bearing SKOV3 cells was established, which successfully expressed pEgr-1-endostatin upon exposure to IR. The changes in endostatin, HIF-1 $\alpha$, VEGF and microvessels were explored in the control, IR-treated and pEgr-1-endostatin-IR-treated groups. Our results suggested that the combination of pEgr-1-endostatin with IR could improve radio-resistance in hypoxic conditions.

\section{Materials and methods}

Cell culture and plasmid. The human ovarian cancer cell line SKOV3 was purchased from the Cell Bank of the Chinese Academy of Sciences (Shanghai, China). SKOV3 cells were routinely maintained in Dulbecco's modified Eagle medium (Invitrogen; Thermo Fisher Scientific, Inc., Waltham, MA, USA) supplemented with $10 \%$ fetal bovine serum (Invitrogen; Thermo Fisher Scientific, Inc.), $100 \mathrm{U} / \mathrm{ml}$ penicillin $\mathrm{G}$ and $100 \mu \mathrm{g} / \mathrm{ml}$ streptomycin, in an incubator with $5 \% \mathrm{CO}_{2}$ at $37^{\circ} \mathrm{C}$ under humidified conditions. The pEgr-1-endostatin plasmid (provided by the Central Laboratory of The Affiliated Hospital of Qingdao University, Qingdao, China) and Lipofectamine 2000 (Gibco; Thermo Fisher Scientific, Inc.) were mixed 1:1 to a final volume of $100 \mu \mathrm{l}$, which contained $50 \mu \mathrm{g}$ plasmid.
Nude mouse xenograft model. The procedures for animal experiments were all approved by the Committee on the Use and Care of Animals of The Affiliated Hospital of Qingdao University (Qingdao, China), and were performed in accordance with ethical standards. A total of $80 \mathrm{BALB} / \mathrm{c}$ nude mice (female; age, 4-5 week-old; weight, 10-13 g) were acquired from Beijing Vital River Laboratory Animal Technology Co. Ltd. [Beijing, China; approval number, SCXK (Beijing) 2006-0010] and were housed under pathogen-free conditions at $27 \pm 1^{\circ} \mathrm{C}$, with a $10 \mathrm{~h}$ light and $14 \mathrm{~h}$ dark cycle. Viable cells were quantified using a cell counting chamber to adjust the total cell concentration to $3 \times 10^{8}$ cells $/ \mathrm{ml}$. The mice skin was disinfected at the point of injection. A total $6 \times 10^{7}$ cells in suspension was injected subcutaneously in the right hind leg of each mouse. Tumor size (in $\mathrm{mm}$ ) was measured directly by pathologists as the largest diameter of the tumor mass.

Group division and administration of IR. When the inoculated primary tumor reached $20.0 \mathrm{~mm}$ in diameter, the 24 mice were randomly divided into three groups with equal number $(n=8)$. The mice in the control group were not subjected to IR. The IR-treated group was locally exposed to $6 \mathrm{MV}$ X-ray with a Clinac 23EX (Varian Medical Systems, Palo Alto, CA, USA), at a dose rate of $300 \mathrm{cGy} / \mathrm{min}$ and source skin distance of $100 \mathrm{~cm}$. The dosage for each mouse was $300 \mathrm{cGy}$. The mice in the endostatin-IR-treated group were also locally exposed to Varian Clinac 23EX 6 MV X-ray under the same conditions and dosage after injection of plasmid for $12 \mathrm{~h}$. The injection of plasmid was performed in five different sites on average. Mice were sacrificed using cervical translocation after $48 \mathrm{~h}$ irradiation, and the intact tumor masses were removed immediately. Samples of the tumors were fixed in formalin for $8 \mathrm{~h}$, and then embedded with paraffin. The remaining tumor tissues were frozen at $-80^{\circ} \mathrm{C}$ in liquid nitrogen for further study.

Reverse transcription-polymerase chain reaction (RT-PCR). Searching the GenBank database (National Center for Biotechnology Information, Bethesda, MD, USA) enabled the identification of the primer sequences used in PCR amplification, which are listed in Table I. All primers used in the present study were designed specifically using Primer Express ${ }^{\circledR}$ Software v3.0.1 (Thermo Fisher Scientific, Inc.). Total RNA was extracted from frozen tumor samples using TRIzol reagent 
A

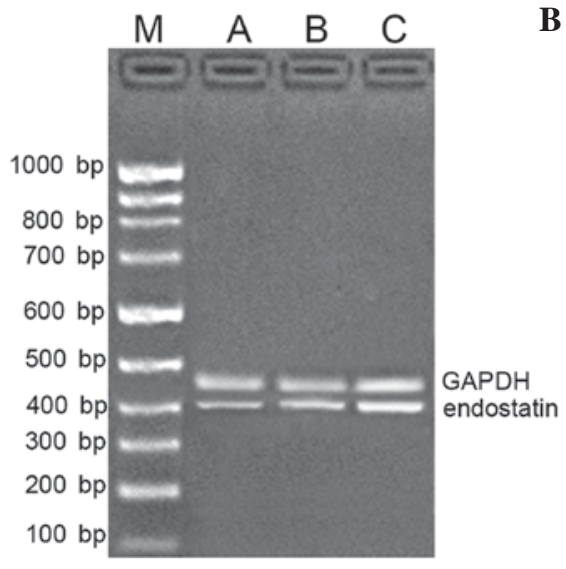

C

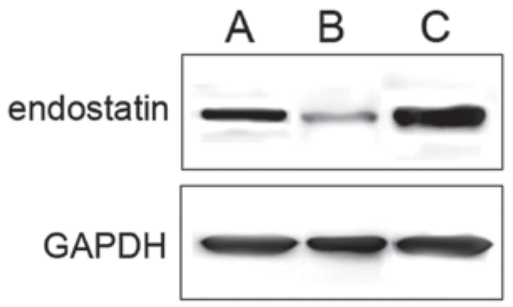

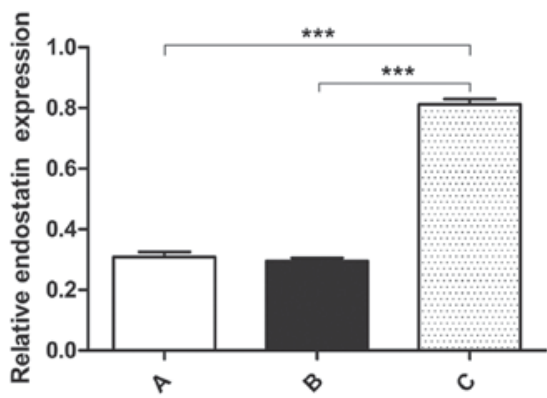

D

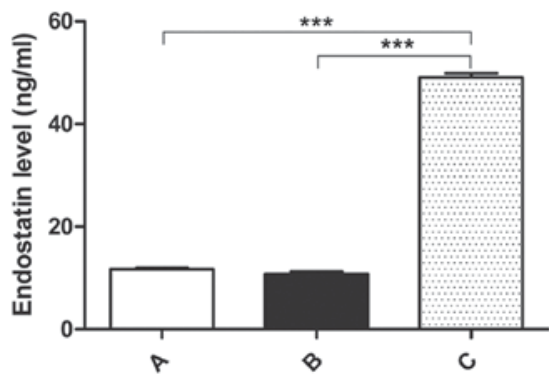

Figure 1. Expression of endostatin in the three groups. (A) Agarose gel electrophoresis results of endostatin mRNA expression, as detected by reverse transcription-polymerase chain reaction in the different groups. (B) The relative mRNA level of endostatin was examined after group C had been injected with pEgr-1-endostatin plasmid for $12 \mathrm{~h}$ and exposed to $300 \mathrm{cGy} / \mathrm{min} \mathrm{X}$-ray for $48 \mathrm{~h}$. Endostatin was successfully increased in the group C compared with that in groups $\mathrm{A}$ and $\mathrm{B}(\mathrm{F}=380.078, \mathrm{P}<0.001)$. (C) The protein level of endostatin was evaluated by western blotting. The results indicated that the expression of endostatin was significantly increased in group $\mathrm{C}$ compared with groups A and $\mathrm{B}(\mathrm{P}=0.039)$. (D) ELISA was used to determine the plasma endostatin level, and the expression of endostatin in group $\mathrm{C}$ was observed to be higher than that in groups $\mathrm{A}(\mathrm{t}=44.770, \mathrm{P}<0.001)$ and $\mathrm{B}(\mathrm{t}=42.480$, $\mathrm{P}<0.001)$. A, control group; $\mathrm{B}$, IR-treated group; C, endostatin-IR-treated group; IR, ionizing radiation; M, marker; mRNA, messenger RNA. ${ }^{* * *} \mathrm{P}<0.001$.

(Gibco; Thermo Fisher Scientific, Inc.). RNA concentration and purity were determined by absorbance (A) 260 and A280 measurements using a NanoDrop ${ }^{\circledR}$ ND-1000 spectrophotometer (Thermo Fisher Scientific, Inc., Pittsburgh, PA, USA). RT-PCR was performed using PCR amplification equipment (Roche Diagnostics, Basel, Switzerland). The PCR reaction mixture consisted of $12.5 \mu \mathrm{l}$ buffer, $10 \mu \mathrm{l}$ RNA, $0.8 \mu \mathrm{l}$ each of the forward and reverse primers for the target genes and for GAPDH, $0.5 \mu \mathrm{l}$ avian myeloblastosis virus (AVM) reverse transcriptase (Takara Bio, Inc., Otsu, Japan), $0.5 \mu 1$ AVM2 Taq polymerase (Takara Bio, Inc.), $4.9 \mu 1$ purified water and $2 \mu \mathrm{l}$ complementary DNA, up to a final volume of $30 \mu \mathrm{l}$. PCR was performed under the following conditions: $60^{\circ} \mathrm{C}$ for $30 \mathrm{~min}$ and $95^{\circ} \mathrm{C}$ for $3 \mathrm{~min}$ for 1 cycle, followed by $95^{\circ} \mathrm{C}$ for $5 \mathrm{sec}$ and $60^{\circ} \mathrm{C}$ for $20 \mathrm{sec}$ for 40 cycles. Upon amplification, the products were loaded onto a $2 \%$ agarose gel in Tris-borate-EDTA buffer for agarose gel electrophoresis at $120 \mathrm{~V}$ for $20 \mathrm{~min}$. The specific bands were visualized with ethidium bromide and photographed under ultraviolet light. A gel scanner system (EP 0241904 B1; Teledyne Isco, Inc., Lincoln, NE, USA) was used for densitometric analysis. The intensity of HIF-1 $\alpha$, VEGF and endostatin PCR products were normalized to that of GAPDH.

ELISA for endostatin. Eye-blood samples from the mice were collected in vivo prior to sacrifice, and the serum was separated by centrifugation $(1,000 \times \mathrm{g})$ for $5 \mathrm{~min}$ at $22-25^{\circ} \mathrm{C}$.
In two indepent experiments, a 100- $\mu 1$ sample was analyzed using an endostatin ELISA kit (Jingmei BioTech Co., Ltd., Beijing, China). The assay was carried out according to the manufacturer's protocol. The absorbance was measured at $450 \mathrm{~nm}$ by an ELISA instrument (BIOBASE2000; Jinan Biobase Biotech Co., Ltd., Jinan, China). The endostatin concentrations were quantified by comparison with a series of endostatin standard samples included in the assay kit. All samples were analyzed in duplicate independently, and readings were obtained in triplicate.

HIF-1 $\alpha$ immunohistochemistry. HIF-1 $\alpha$ immunohistochemistry for hypoxic tumor cells was performed on 4- $\mu$ m-thick sections of formalin-fixed, paraffin-embedded tissues. HIF1- $\alpha$ was detected with a rabbit anti-mouse monoclonal antibody (1:300 dilution; \#AH339-1; Abcam, Cambridge, UK) following overnight incubation at $4^{\circ} \mathrm{C}$. The procedures followed a semi-quantitative criteria: Slides were first scanned at x100 magnification, and 10 cellular fields were randomly selected, from which, 200 cells and the number of HIF-1 $\alpha$-positive cancer cells were counted. The results were interpreted by two investigators without knowledge of the corresponding clinicopathological data. Immunohistochemical staining was assessed semi-quantitatively by measuring both the intensity of the staining ( 0 for non-staining; 1 for yellow staining; 2 for brown-yellow staining; and 3 for brown staining) and the quantity of the staining $(0,0-5 \% ; 1,5-25 \% ; 2,25-50 \%$; 

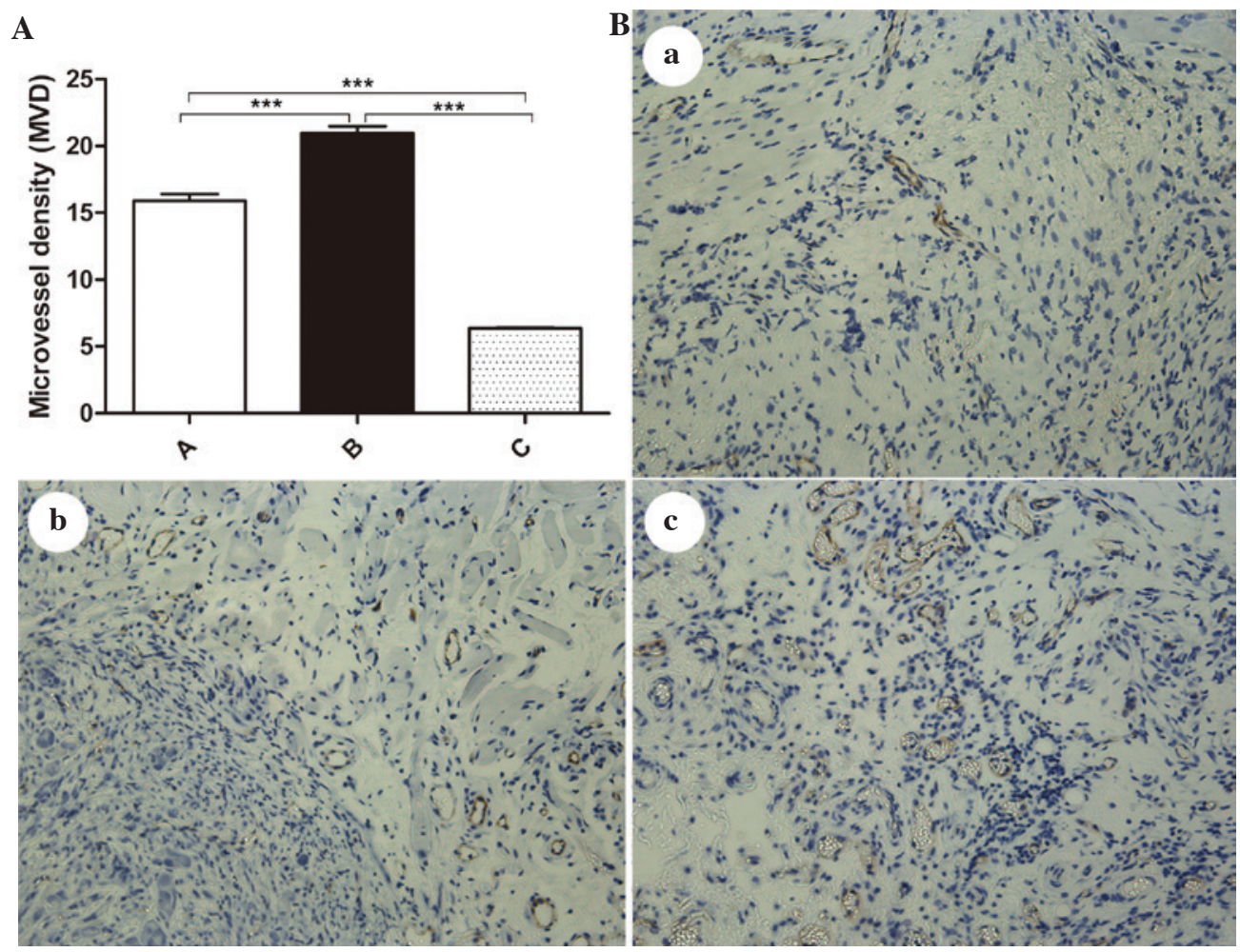

Figure 2. MVD in tumor tissues. (A) The MVD counts for each group were significantly different among the different groups ( $\mathrm{F}=22.660$, $\mathrm{P}<0.001)$. An obvious increase in MVD was observed in group B (20.970 \pm 1.410$)$ compared with that in group A $(15.890 \pm 1.476, t=7.040, P<0.001)$, while a significant decrease in MVD was observed in group C $(6.366 \pm 0.155)$ compared with that in groups $A(t=18.153, P<0.001)$ and $B(t=29.120, P<0.001)$. (B) Tumor microvessels were identified by cluster of differentiation 31 immunohistochemistry (magnification, $\mathrm{x} 200$ ). Comparison of the morphology of the tumor vasculature in the three groups revealed that the microvessels in the (a) endostatin-IR-treated group were more regularly distributed and had fewer giant branches than those in the (b) control and (c) IR-treated groups. A, control group; B, IR-treated group; C, endostatin-IR-treated group; IR, ionizing radiation; MVD, microvessel density. **** $\mathrm{P}<0.001$

3, 50-75\%; and 4, 75-100\%). Raw data were converted to immunohistochemical score (IHS) by combining the quantity score (0-4) with the staining intensity score (0-3). The final scores could range from 0 to 7 . An IHS of 6-7 was considered strong immunoreactivity; 3-5, moderate; $1-2$, weak; and 0, negative (22). The final scoring was achieved by comparing the scores between the observers, and any discrepancies were resolved by consensus. In case of disagreement, the slides were re-examined, and consensus was reached by the observers.

Western blotting. Tissues were lysed using radioimmunoprecipitation assay buffer (Sigma-Aldrich; Merck Millipore, Darmstadt, Germany). The soluble protein concentration was determined by the Bradford method. Total protein $(10 \mu \mathrm{g})$ was resolved on 10-15\% SDS-PAGE and electro-transferred onto polyvinylidene difluoride membranes. The membranes were blocked with PBS containing $1 \%$ Tween 20 at $4^{\circ} \mathrm{C}$ overnight, washed and incubated overnight at $4^{\circ} \mathrm{C}$ with anti-HIF-1 $\alpha$ (\#AH339-2) and anti-endostatin (\#BAF1098) primary antibodies (1:1,000 dilution in TBS-T; Bioworld Technology, Inc., St. Louis Park, MN, USA). Upon being washed, membranes were incubated for $1 \mathrm{~h}$ at $22-25^{\circ} \mathrm{C}$ with the corresponding secondary antibodies (1:1,200 dilution in TBS-T; \#A00131-1; Abcam) for $1 \mathrm{~h}$ at room temperature. The immunoblots were detected using an electrochemiluminescence kit (Pierce Biotechnology, Inc., Rockford, IL, USA) and exposed to the Fusion FX5 automatic gel imaging analysis system (Vilber Lourmat, Marne-La-Vallée, France).
Cluster of differentiation (CD)31 immunohistochemistry and microvessel density (MVD) assessment. CD31 immunohistochemistry for tumor blood vessels was performed on 4- $\mu$ m-thick sections of formalin-fixed, paraffin-embedded tissues. CD31 was detected with a rabbit anti-mouse monoclonal antibody (anti-CD31; 1:200 dilution; \#31-1006-00; Abcam). Following deparaffinization and rehydration, tissue sections were treated with $3 \% \mathrm{H}_{2} \mathrm{O}_{2}$ for 20 min to block the endogenous peroxidase activity. Sections were washed three times in PBS for $5 \mathrm{~min}$, and incubated for $20 \mathrm{~min}$ at room temperature with a protein-blocking solution consisting of PBS with 10\% goat serum (\#16210064; Thermo Fisher Scientific, Inc.). Excess blocking solution was drained, and the anti-CD31 primary antibody reaction was carried out at $4^{\circ} \mathrm{C}$ overnight. Next, sections were washed three times with PBS for $5 \mathrm{~min}$, and subsequently incubated with biotin-labeled anti-rabbit immunoglobulin G (1:50 dilution; \#A21068; Abcam) for $30 \mathrm{~min}$ at $37^{\circ} \mathrm{C}$. Following three washes, horseradish peroxidase-conjugated streptavidin (Thermo Fisher Scientific, Inc.) was added to the sections, incubated at $37^{\circ} \mathrm{C}$ for $30 \mathrm{~min}$ and washed three times with PBS (5 min each). 3,3'-Diaminobenzidine was used to detect antigen-antibody binding. Counterstaining was performed with hematoxylin, and following dehydration, slides were mounted with glycerogelatin. In order to evaluate the MVD on the CD31-stained tumor and corresponding non-tumor tissue sections, the hot-spots method was utilized, as previously described (11). The average count of microvessels in 10 fields was calculated 
A

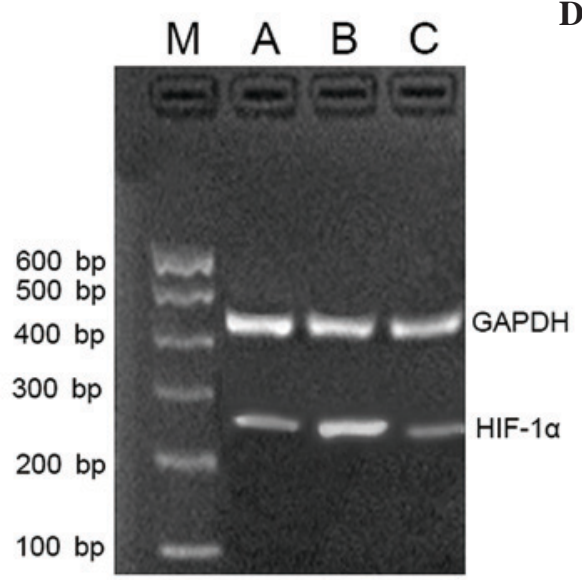

B

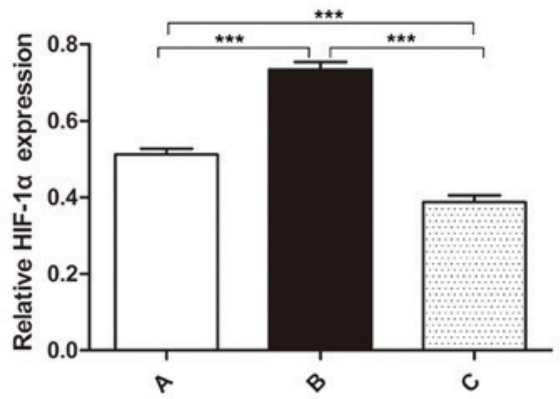

C

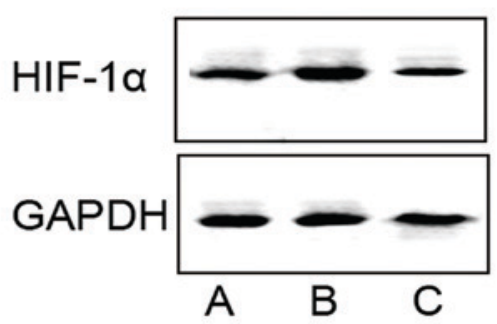

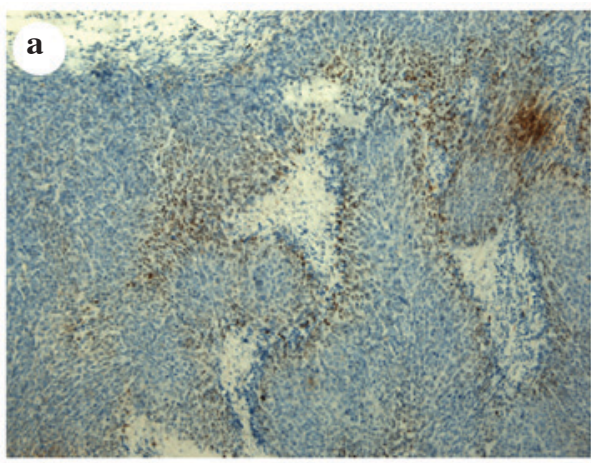
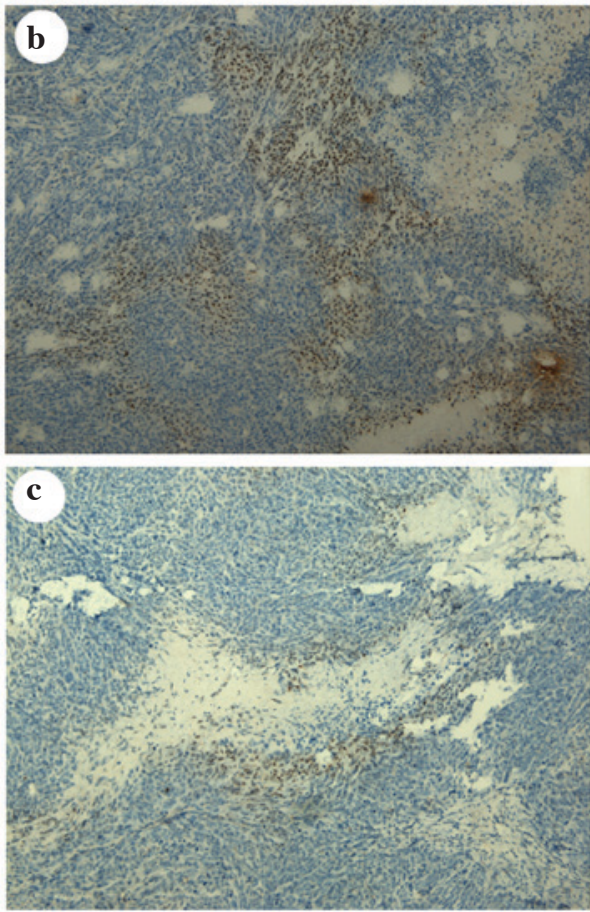

Figure 3. Expression of HIF-1 $\alpha$ in tumor tissues. (A) Agarose gel electrophoresis results of HIF-1 $\alpha$ mRNA expression, as evaluated by reverse transcription-polymerase chain reaction in different groups. (B) Relative levels of HIF-1 $\alpha$ mRNA in different groups. The difference was statistically significant in the three groups: Groups $\mathrm{A}$ and $\mathrm{B}(\mathrm{t}=8.961, \mathrm{P}<0.001)$; groups $\mathrm{A}$ and $\mathrm{C}(\mathrm{t}=5.339, \mathrm{P}=0.001)$; groups $\mathrm{B}$ and $\mathrm{C}$ ( $\mathrm{t}=12.930$, $\mathrm{P}<0.001)$. $(\mathrm{C})$ The protein level of HIF-1 $\alpha$ was analyzed by western blotting. A higher average optical density value for HIF-1 $\alpha$ was observed in group B compared with that in groups A and C. The difference was statistically significant ( $\mathrm{P}=0.046)$. (D) Immunohistochemistry assessment indicated that the expression of HIF-1 $\alpha$ was (a) moderate in the control group; (b) strong in the IR-treated group; and (c) weak in the endostatin-IR-treated group (magnification, x200). A, control group; B, IR-treated group; $\mathrm{C}$, endostatin-IR-treated group; IR, ionizing radiation; M, marker; mRNA, messenger RNA; HIF, hypoxia-inducible factor. ${ }^{* * *} \mathrm{P}<0.001$.

at x200 magnification using the Chalkley counting method of vessel hot spots (11).

Statistics analysis. SPSS 19.0 software (IBM SPSS, Armonk, NY, USA) and GraphPad Prism 5.0 software (GraphPad Software, Inc., La Jolla, CA, USA) were used for data analysis. The levels of endostatin, CD31, HIF-1 $\alpha$ and VEGF transcription were presented as the mean \pm standard deviation. One-way analysis of variance was performed for comparison among the different groups, and subsequently, the Student's $t$-test was applied for statistical analysis between the groups. $\mathrm{P}<0.05$ was considered to indicate a statistically significant difference.

\section{Results}

Expression of endostatin in the three groups. The expression level of endostatin messenger (m) RNA was detected using
RT-PCR after $48 \mathrm{~h}$ of irradiation. All groups exhibited certain expression of endostatin (Fig. 1A and B). The relative mRNA expression for the three groups was $0.309 \pm 0.0165,0.295 \pm 0.0293$ and $0.813 \pm 0.495$, respectively. The level of endostatin in the endostatin-IR-treated group was significantly higher than that in the control and the IR-treated groups $(\mathrm{F}=380.078, \mathrm{P}<0.001)$. No significant differences were observed between the control group and the IR-treated group $(t=0.705, \mathrm{P}=0.492)$. The expression of endostatin was further detected using western blotting. The gray scale of the stained area was determined under identical conditions in the different groups. The results demonstrated that the expression of endostatin was significantly increased in the endostatin-IR-treated group compared with the control and IR-treated groups $(\mathrm{P}=0.039)$ (Fig. 1C). ELISA was used to determine the plasma endostatin level, and confirmed the aforementioned results of endostatin expression in the endostatin-IR-treated, IR-treated and endostatin-treated groups (Fig. 1D). The results obtained were as follows: 
$\mathbf{A}$

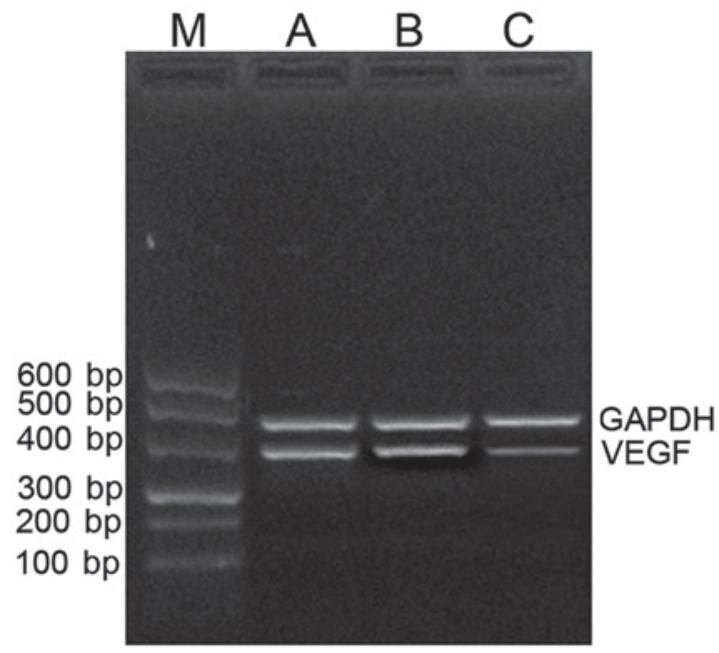

B

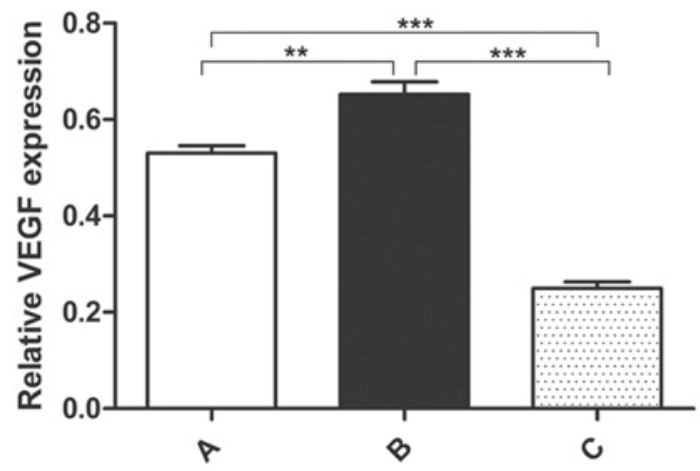

Figure 4. Expression of VEGF in tumor tissues. (A) Agarose gel electrophoresis results of VEGF mRNA expression in tumor tissues, as detected by reverse transcription-polymerase chain reaction. (B) A significant difference was observed in the three groups $(\mathrm{F}=119.691, \mathrm{P}<0.001)$. Compared with group A $(0.530 \pm 0.0444)$, the relative VEGF mRNA expression was increased in group $\mathrm{B}(0.653 \pm 0.0727, \mathrm{P}=0.001)$ but decreased in group $\mathrm{C}(0.250 \pm 0.0359, \mathrm{P}<0.001)$. The expression of VEGF in group $\mathrm{C}$ was significantly lower than that in group $\mathrm{B}(\mathrm{t}=14.050, \mathrm{P}<0.001)$. A, control group; $\mathrm{B}$, IR-treated group; $\mathrm{C}$, endostatin-IR-treated group; VEGF, vascular endothelial growth factor; IR, ionizing radiation; mRNA, messenger RNA. ${ }^{* *} \mathrm{P} \geq 0.001$ and $<0.05 ;{ }^{* * *} \mathrm{P}<0.001$.

Control group, $11.73 \pm 0.65 \mathrm{ng} / \mathrm{ml}$ endostatin; IR-treated group, $10.85 \pm 1.15 \mathrm{ng} / \mathrm{ml}$ endostatin; and endostatin-IR-treated group, $49.07 \pm 2.27 \mathrm{ng} / \mathrm{ml}$ endostatin. There was no significant difference between the control group and the IR-treated group $(t=1.885, \mathrm{P}=0.0804)$. The expression of endostatin in the endostatin-IR-treated group was higher than that in the control group $(t=44.770, \mathrm{P}<0.001)$ and the IR-treated group $(t=42.480$, $\mathrm{P}<0.001)$. Our results indicated that the endostatin level in the endostatin-IR-treated group was successfully increased at both the mRNA and protein level.

$M V D$. Tumor microvessels were labeled by CD31 and assessed by counting MVD (Fig. 2A and B). The MVD counts for each group were as follows: Control group, 15.890 \pm 1.476 microvessels; IR-treated group, 20.970 \pm 1.410 microvessels; and endostatin-IR-treated group, 6.366 \pm 0.155 microvessels. The MVD levels were significantly different among the different groups $(\mathrm{F}=22.660, \mathrm{P}<0.001)$ (Fig. 2A). An obvious increase in MVD was observed in the IR-treated group compared with that in the control group $(t=7.040, \mathrm{P}<0.001)$, and a significant decrease was observed in the endostatin-IR-treated group compared with that in the control $(t=18.153, \mathrm{P}<0.001)$ and IR-treated groups $(t=29.120, \mathrm{P}<0.001)$. By comparing the morphology of the tumor vasculature in the three groups it was observed that the microvessels in the endostatin-IR-treated group were more regularly distributed and had fewer giant branches than those in the IR-treated group (Fig. 2B).

Expression of HIF-1 $\alpha$ in the three groups. The mRNA expression levels of HIF- $1 \alpha$ in the three groups were $0.513 \pm 0.042$, $0.734 \pm 0.056$ and $0.388 \pm 0.051$, respectively. The difference was statistically significant in the three groups $(F=98.410$, $\mathrm{P}<0.001$ ) (Fig. 3A and B). Compared with the control group, the expression of HIF-1 $\alpha$ increased significantly in the IR-treated group ( $t=8.961, \mathrm{P}<0.001)$, while it decreased significantly in the endostatin-IR-treated group $(t=5.339, \mathrm{P}=0.001)$. A significant difference was noted between the IR-treated group and the endostatin-IR-treated group $(t=12.930, \mathrm{P}<0.001)$. Western blotting was used to analyze the expression of HIF-1 $\alpha$ at the protein level. A higher average optical density for HIF-1 $\alpha$ was observed in the IR-treated group compared with that in the control and the endostatin-IR-treated groups (Fig. 3C). The difference was statistically significant $(\mathrm{P}=0.046)$. Immunohistochemistry assessment revealed various expression levels for HIF-1 $\alpha$, with moderate staining in the control group, strong staining in the IR-treated group and weak staining in the endostatin-IR-treated group (Fig. 3D).

Expression of VEGF in the three groups. VEGF is a downstream target of HIF-1 $\alpha$, and both VEGF and HIF-1 $\alpha$ are 
major regulators of angiogenesis in numerous types of cancer $(23,24)$. The present study detected VEGF mRNA expression using RT-PCR, and a significant difference was observed in the three groups $(\mathrm{F}=119.691, \mathrm{P}<0.001)$ (Fig. 4A and $\mathrm{B})$. The relative VEGF mRNA expression was increased in the IR-treated group $(0.653 \pm 0.073, t=4.069, \mathrm{P}=0.0011)$ but it was decreased in the endostatin-IR-treated group $(0.250 \pm 0.036, t=13.880, \mathrm{P}<0.001)$, compared with that in the control group $(0.530 \pm 0.044)$. Compared with the IR-treated group, the low expression of VEGF was significantly different in the endostatin-IR-treated group $(t=14.050, \mathrm{P}<0.001)$.

\section{Discussion}

Tumor hypoxia, which occurs mainly as a result of inadequate tissue perfusion in solid tumors, is a well-known challenge for successful radiotherapy (25). Various strategies to overcome hypoxia-related radio-resistance in solid tumors have been developed, including hypoxic sensitizers, hyperbaric oxygen and angiogenesis inhibitors $(26,27)$. Endostatin is a potentially effective angiogenesis inhibitor, and has been modified for clinical application (28). However, reports on the combination of pEgr-1-endostatin with IR for the treatment of angiogenesis and radio-resistance in solid tumors are limited.

Angiogenesis has an essential role in the formation of a new vascular network to supply nutrients and oxygen and to remove waste products (29). Newly formed microvessels in hypoxic conditions do not present a normal morphology, which results in radio-resistance in the majority of solid tumors during radiotherapy (30). In order to explore the effect of endostatin in preventing radio-resistance during IR treatment, a nude mouse model bearing SKOV3 ovarian carcinoma was established in the present study, and the mice were divided into three groups. Following injection of pEgr-1-endostatin plasmid for $12 \mathrm{~h}$, the mice in the endostatin-IR-treated group were exposed to IR for $48 \mathrm{~h}$, and the IR-treated group was exposed to the same condition. Our results indicated that endostatin was successfully increased in the endostatin-IR-treated group compared with that in the control and the IR-treated groups. This is consistent with our previous study's finding that the anti-tumor effects of pEgr-1-endostatin-tumor necrosis factor- $\alpha$ recombinant plasmid expression were successfully induced by IR (18). Administration of endostatin in vivo led to a strong suppression of tumor-induced angiogenesis (17). In our study, it was observed that tumor MVD was decreased significantly following administration of IR in the endostatin-IR-treated group, and the morphology of the tumor vasculature revealed that the microvessels were regularly distributed and had less giant branches than those in the IR-treated group. Our findings indicated that the expression of pEgr-1-endostatin was successfully induced by IR, and suggested that endostatin may improve radio-resistance by normalizing the tumor vasculature.

Hypoxia is a major pro-angiogenic phenomenon in solid tumors that promotes angiogenesis via the HIF-1 transcription factor complex (31). VEGF gene expression is upregulated in hypoxia via the oxygen sensor HIF-1 $\alpha$, and both VEGF and HIF- $1 \alpha$ are the main regulators of angiogenesis $(22,23,32)$. In the process of angiogenesis, the endostatin plays a facilitating role in the apoptosis of endothelial cells; meanwhile, it plays a counteracting role in the proliferation of endothelial cells $(33,34)$. In the present study, the expression of HIF-1 $\alpha$ and VEGF at the mRNA and protein level were further explored in the three groups. It was observed that both HIF-1 $\alpha$ and VEGF were significantly increased in the IR-treated group, while they were decreased in the endostatin-IR-treated group, compared with those in the control group. These findings suggested that IR treatment for solid tumors may result in hypoxia by increasing irregular microvessels, due to aberrant expression of HIF-1 $\alpha$ and VEGF. In addition, our results indicated that endostatin combined with IR can downregulate the expression of HIF-1 $\alpha$ and VEGF, which ultimately decreases the number of abnormal microvessels. Thus, it may be concluded that endostatin can improve IR-induced hypoxia, which, combined with IR, may be a new treatment for solid tumors. These results are consistent with the study of Mauceri et al, who reported that the cytotoxic effect of the combination of an angiogenic inhibitor with IR on endothelial cells was more effective than that of single IR treatment (32). The HIF-1/VEGF signaling pathway may be the possible mechanism for the endostatin-mediated normalizing effects on vessels. Increasing evidences also indicated that endostatin may suppress endothelial cell proliferation and preclude the subsequent recruitment of new vasculature by activating downstream apoptotic signals or by blocking the activation and catalytic activity of matrix metalloproteinases $(33,34)$. Thus, further experiments should be performed in order to clarify these observations.

In conclusion, IR could induce angiogenesis, which resulted in hypoxia, and endostatin decreased the number of microvessels via the HIF-1/VEGF signaling pathway. The present results also indicated that $\mathrm{pEgr-1-endostatin} \mathrm{combined}$ with IR may be a new strategy for treating solid tumors. However, the limitation of our study is that the mechanism of endostatin in preventing radio-resistance was not explored in depth. Future in vitro and in vivo studies are required on this combined treatment for solid tumors.

\section{Acknowledgements}

The present study was supported by a program from Qingdao Municipal Science and Technology Commission [Qingdao, China; grant no. 2012-1-3-2-(13)-nsh].

\section{References}

1. Gray LH, Conger AD, Ebert M, Hornsey S and Scott OC: The concentration of oxygen dissolved in tissues at the time of irradiation as a factor in radiotherapy. Br J Radiol 26: 638-648, 1953.

2. Moulder JE and Rockwell S: Tumor hypoxia: Its impact on cancer therapy. Cancer Metastasis Rev 5: 313-341, 1987.

3. Holzer LA, Cör A, Pfandlsteiner G and Holzer G: Expression of VEGF, its receptors and HIF-1 $\alpha$ in Dupuytren's disease. Acta Orthop 84: 420-425, 2013.

4. Brahimi-Horn MC, Chiche J and Pouyssegur J: Hypoxia and cancer. J Mol Med (Berl) 85: 1301-1307, 2007.

5. Vaupel P, Hockel M and Mayer A: Detection and characterization of tumor hypoxia using pO2 histography. Antioxid Redox Signal 9: 1221-1235, 2007.

6. Multhoff G, Radons J and Vaupel P: Critical role of aberrant angiogenesis in the development of tumor hypoxia and associated radioresistance. Cancers (Basel) 6: 813-828, 2014.

7. Ikeda E: Cellular response to tissue hypoxia and its involvement in disease progression. Pathol Int 55: 603-610, 2005. 
8. SalcedaSandCaroJ:Hypoxia-induciblefactor 1alpha(HIF-1alpha) protein is rapidly degraded by the ubiquitin-proteasome system under normoxic conditions. Its stabilization by hypoxia depends on redox-induced changes. J Biol Chem 272: 22642-22647, 1997.

9. Semenza GL: Targeting HIF-1 for cancer therapy. Nat Rev Cancer 3: 721-732, 2003.

10. Arjamaa O, Nikinmaa M, Salminen A and Kaarniranta K: Regulatory role of HIF-1alpha in the pathogenesis of age-related macular degeneration (AMD). Ageing Res Rev 8: 349-358, 2009.

11. Zhang P, Zhang X, Hao X, Wang Y, Hui Y, Wang H, Hu D and Zhou J: Racl activates HIF-1 in retinal pigment epithelium cells under hypoxia. Graefes Arch Clin Exp Ophthalmol 247: 633-639, 2009.

12. Semenza GL: Regulation of mammalian O2 homeostasis by hypoxia-inducible factor 1 . Annu Rev Cell Dev Biol 15: 551-578, 1999.

13. Tammela T, Zarkada G, Nurmi H, Jakobsson L, Heinolainen K, Tvorogov D, Zheng W, Franco CA, Murtomäki A, Aranda E, et al: VEGFR-3 controls tip to stalk conversion at vessel fusion sites by reinforcing Notch signalling. Nat Cell Biol 13: 1202-1213, 2011.

14. Semenza GL: HIF-1 and human disease: One highly involved factor. Genes Dev 14: 1983-1991, 2000.

15. Jain RK: Normalization of tumor vasculature: An emerging concept in antiangiogenic therapy. Science 307: 58-62, 2005.

16. Ke QH, Zhou SQ, Huang M, Lei Y, Du W and Yang JY: Early efficacy of Endostar combined with chemoradiotherapy for advanced cervical cancers. Asian Pac J Cancer Prev 13: 923-926, 2012.

17. O'Reilly MS, Boehm T, Shing Y, Fukai N, Vasios G, Lane WS, Flynn E, Birkhead JR, Olsen BR and Folkman J: Endostatin: An endogenous inhibitor of angiogenesis and tumor growth. Cell 88: 277-285, 1997.

18. Qi X, Liu Y, Wei W, Huang X and Zuo Y: Effects of the C-terminal of endostatin on the tumorigenic potential of $\mathrm{H} 22$ cells. Biomed Rep 1: 761-765, 2013.

19. Huang RP and Adamson ED: A biological role for Egr-1 in cell survival following ultra-violet irradiation. Oncogene 10: 467-475, 1995.

20. Zhang Y, Qiu W, Liang J, Yu Z and Yue L: Anti-tumor effects of pEgr-1-endostatin-TNF- $\alpha$ recombinant plasmid expression induced by ionizing radiation. Asian Pac J Cancer Prev 12: 2933-2937, 2011

21. El-Gendi S and Abdel-Hadi M: Lymphatic vessel density as prognostic factor in breast carcinoma: Relation to clinicopathologic parameters. J Egypt Natl Canc Inst 21: 139-149, 2009.

22. Ferrara $\mathrm{N}$ and Davis-Smyth T: The biology of vascular endothelial growth factor. Endocr Rev 18: 4-25, 1997.
23. Cao D, Hou M, Guan YS, Jiang M, Yang Y and Gou HF: Expression of HIF-1alpha and VEGF in colorectal cancer: Association with clinical outcomes and prognostic implications. BMC Cancer 9: 432, 2009.

24. Wilson WR and Hay MP: Targeting hypoxia in cancer therapy. Nat Rev Cancer 11: 393-410, 2011

25. Li L, Huang JL, Liu QC, Wu PH, Liu RY, Zeng YX and Huang WL: Endostatin gene therapy for liver cancer by a recombinant adenovirus delivery. World J Gastroenterol 10: 1867-1871, 2004.

26. Yoshimura M, Itasaka S, Harada $\mathrm{H}$ and Hiraoka M: Microenvironment and radiation therapy. Biomed Res Int 2013: 685308, 2013.

27. Wang J, Sun Y, Liu Y, Yu Q, Zhang Y, Li K, Zhu Y, Zhou Q, Hou M, Guan Z, et al: Results of randomized, multicenter, double-blind phase III trial of rh-endostatin (YH-16) in treatment of advanced non-small cell lung cancer patients. Zhongguo Fei Ai Za Zhi 8: 283-290, 2005 (In Chinese).

28. Folkman J: Tumor angiogenesis: Therapeutic implications. N Engl J Med 285: 1182-1186, 1971.

29. Forsythe JA, Jiang BH, Iyer NV, Agani F, Leung SW, Koos RD and Semenza GL: Activation of vascular endothelial growth factor gene transcription by hypoxia-inducible factor 1 . Mol Cell Biol 16: 4604-4613, 1996

30. Brizel DM, Scully SP, Harrelson JM, Layfield LJ, Bean JM, Prosnitz LR and Dewhirst MW: Tumor oxygenation predicts for the likelihood of distant metastases in human soft tissue sarcoma. Cancer Res 56: 941-943, 1996.

31. Lohela M, Bry M, Tammela T and Alitalo K: VEGFs and receptors involved in angiogenesis versus lymphangiogenesis. Curr Opin Cell Biol 21: 154-165, 2009.

32. Mauceri HJ, Beckett MA, Liang H, Sutton HG, Pitroda S, Galka E, Efimova E, Darga T, Khodarev NN, King CR, et al: Translational strategies exploiting TNF-alpha that sensitize tumors to radiation therapy. Cancer Gene Ther 16: 373-381, 2009.

33. Kim YM, Jang JW, Lee OH, Yeon J, Choi EY, Kim KW, Lee ST and Kwon YG: Endostatin inhibits endothelial and tumor cellular invasion by blocking the activation and catalytic activity of matrix metalloproteinase. Cancer Res 60: 5410-5413, 2000.

34. Rehn M, Veikkola T, Kukk-Valdre E, Nakamura H, Ilmonen M, Lombardo C, Pihlajaniemi T, Alitalo K and Vuori K: Interaction of endostatin with integrins implicated in angiogenesis. Proc Natl Acad Sci USA 98: 1024-1029, 2001. 